\title{
Anxiety affects disability and quality of life in patients with painful diabetic neuropathy
}

Citation for published version (APA):

Geelen, C. C., Smeets, R. J. E. M., Schmitz, S., van den Bergh, J. P., Goossens, M. E. J. B., \& Verbunt, J. A. (2017). Anxiety affects disability and quality of life in patients with painful diabetic neuropathy. European Journal of Pain, 21(10), 1632-1641. https://doi.org/10.1002/ejp.1067

Document status and date:

Published: 01/11/2017

DOI:

10.1002/ejp.1067

Document Version:

Publisher's PDF, also known as Version of record

Document license:

Taverne

Please check the document version of this publication:

- A submitted manuscript is the version of the article upon submission and before peer-review. There can be important differences between the submitted version and the official published version of record.

People interested in the research are advised to contact the author for the final version of the publication, or visit the DOI to the publisher's website.

- The final author version and the galley proof are versions of the publication after peer review.

- The final published version features the final layout of the paper including the volume, issue and page numbers.

Link to publication

\footnotetext{
General rights rights.

- You may freely distribute the URL identifying the publication in the public portal. please follow below link for the End User Agreement:

www.umlib.nl/taverne-license

Take down policy

If you believe that this document breaches copyright please contact us at:

repository@maastrichtuniversity.nl

providing details and we will investigate your claim.
}

Copyright and moral rights for the publications made accessible in the public portal are retained by the authors and/or other copyright owners and it is a condition of accessing publications that users recognise and abide by the legal requirements associated with these

- Users may download and print one copy of any publication from the public portal for the purpose of private study or research.

- You may not further distribute the material or use it for any profit-making activity or commercial gain

If the publication is distributed under the terms of Article $25 \mathrm{fa}$ of the Dutch Copyright Act, indicated by the "Taverne" license above, 


\title{
Anxiety affects disability and quality of life in patients with painful diabetic neuropathy
}

\author{
C.C. Geelen ${ }^{1,2}$, R.J.E.M. Smeets ${ }^{2,3}$, S. Schmitz ${ }^{2}$, J.P. van den Bergh ${ }^{4,5}$, M.E.J.B. Goossens ${ }^{2}$, J.A. Verbunt ${ }^{1,2}$ \\ 1 Adelante Centre of Expertise in Rehabilitation and Audiology, Hoensbroek, The Netherlands \\ 2 Department of Rehabilitation Medicine, Research School CAPHRI, Maastricht University, Maastricht, The Netherlands \\ 3 Libra Rehabilitation and Audiology, Eindhoven, The Netherlands \\ 4 Department of Internal Medicine, VieCuri Medical Centre, Venlo, The Netherlands \\ 5 Department of Internal Medicine, Research School NUTRIM, Maastricht University, The Netherlands
}

Correspondence

Charlotte C. Geelen

E-mail: c.geelen@adelante-zorggroep.nl

\section{Funding sources}

This work was partially supported by a grant

from the Dutch Diabetes Foundation.

Conflicts of interest

None declared.

Accepted for publication

16 May 2017

doi:10.1002/ejp.1067

\begin{abstract}
Background: Painful diabetic neuropathy (PDN) is known to negatively affect psychosocial functioning as expressed by enhanced levels of anxiety and depression. The aim of this study was to specify diabetes and pain-related fears.
\end{abstract}

Methods: This questionnaire-based cross-sectional study included 154 patients with PDN (mean age $65.7 \pm 6.6$ years). Correlation analyses corrected for age, gender, pain intensity, pain duration and insulin treatment were performed to assess the associations of fear of hypoglycaemia (Hypoglycaemia Fear Survey, HFS), kinesiophobia (Tampa Scale of Kinesiophobia, TSK), fear of pain (Pain Anxiety Symptom Scale, PASS-20), fear of falling (Falls Efficacy Scale-I, FES-I), fear of fatigue (Tampa Scale of Fatigue, TSF) and fear of negative evaluation (Brief Fear of Negative Evaluation Scale, BFNE), with quality of life (QoL) (Norfolk Quality of Life Questionnaire, Diabetic Neuropathy Version, QOL-DN) and disability (Pain Disability Index, PDI), respectively.

Results: In univariate analyses, all fears were independently associated with QOL-DN and PDI $(p<0.001$ for all variables). Linear regression models including all fears and confounders, showed that pain intensity, pain duration and FES-I were significantly associated with QOL-DN $\left(R^{2}=0.603\right)$. Pain intensity, male gender and FES-I were significantly associated with PDI $\left(R^{2}=0.526\right)$.

Conclusions: After controlling for confounders, levels of pain intensity, duration of pain and fear of falling were negatively associated with QoL in patients with PDN. Pain intensity, male gender and fear of falling were positively associated with disability. Specifying fears enables us to identify potential targets for behavioural interventions that aim to improve psychosocial well-being in patients with PDN.

Significance: This study shows that patients with PDN suffer from various fears, which should enable us to design a treatment strategy that directly targets these fears, hereby improving physical and psychosocial well-being in these patients.

\section{Introduction}

Peripheral neuropathic pain is defined as pain arising as a direct consequence of a lesion or disease affecting the peripheral nervous system (Treede et al., 2008). Approximately $25-30 \%$ of the patients with diabetes mellitus (DM) develop Painful diabetic 
neuropathy (PDN) (Daousi et al., 2004; Davies et al., 2006). Patients with PDN report a sharp, stinging, electrical, burning sensation that aggravates at night with numbness or loss of sensation of the involved area (Boulton et al., 2004).

Painful diabetic neuropathy is a complex and multi-dimensional condition which is known to negatively affect psychosocial functioning as expressed by enhanced levels of anxiety and depression, potentially leading to pain-related disability (Gore et al., 2005), which can have a major impact on recreational activities, work, general activities, social activities, mobility, sleep and elevated levels of experienced stress (Galer et al., 2000). Fear may also negatively influence glycaemic control in diabetic patients (Collins et al., 2009).

The interpretation of pain and its consequences on daily life are influenced by behavioural and cognitive efforts used in the attempt of dealing with pain (Vlaeyen et al., 2002). Biopsychosocial models regarding chronic pain such as the fear-avoidance model, have been extensively studied in patients with chronic musculoskeletal pain (Leeuw et al., 2007; Van Damme and Kindermans, 2015), but only limited information is available about the way patients with PDN interpret their pain. For this reason, our research group is currently investigating the role of psychosocial factors on physical activity, disability and quality of life (QoL) in patients with PDN.

Research in the current sample has shown that pain catastrophizing was associated with increased disability and decreased QoL in patients with PDN. Interestingly, pain catastrophizing was associated with the subjective feeling of loss of physical activities due to the pain, while it was not associated with the estimated actual level of activity (Geelen et al., 2017).

To gain more insights in the psychological processes that lead to disability and QoL in patients with PDN, we felt that it is important to further investigate and specify anxiety and fears. Improving psychological well-being and especially the level of fear might break this potential vicious cycle in patients with PDN (Collins et al., 2009).

The first step in specifying PDN-related fears was a qualitative study using focus group interviews. In this study, we investigated several PDN-related consequences and fears that seemed to inhibit mobility and decrease QoL in patients with PDN. These consequences of PDN were both physical (weakness, pain, physical restrictions), psychological (feelings of loss, feelings of depression, fear, anger, sadness) and social (social withdrawal, isolation, work limitations, lower career opportunities). The patients reported several fears related to diabetes and pain, such as fear of hypoglycaemia, fear of (increased) pain, fear of total exhaustion, fear of physical injury, fear of falling, fear of loss of identity and fear of negative evaluation (Kanera et al., Submitted).

To further quantify these fears, we identified available validated questionnaires that match these selfreported fears, each measuring one specific element of diabetes-related fear or pain-related fear. From these data, we also developed the Painful diabetic neuropathy Anxiety Rasch Transformed Questionnaire (PART-Q30C) (Geelen et al., 2016). In this study, we have investigated which of these fears showed the largest association with disability and QoL.

\section{Methods}

\subsection{Patients}

An invitational letter explaining the study and requesting participation was sent out to a random selection of 2142 patients as part of a registry of patients with type 2 diabetes from a regional hospital in the south of the Netherlands (VieCuri, Venlo, The Netherlands). Eligibility was based on the following: providing written informed consent, having type 2 diabetes mellitus, aged >18 years, suffering from peripheral polyneuropathy (Diabetic Neuropathy Symptom Score, DNS $\geq 1$; Meijer et al., 2002) and neuropathic pain in the feet (Douleur Neuropathique 4 questions [DN4 $\geq 4$ ]) for at least three months, but being clinically stable. Patients were excluded if there were other conditions that could lead to pain in the feet and/or damage to the peripheral nervous system. Informed consent was obtained from all subjects and the Medical Ethics Committee of Maastricht University, the Netherlands approved the study protocol (11-4-045.4). The full recruitment and inclusion procedure is described elsewhere (Geelen et al., 2017).

\subsection{Measures}

All data were retrieved by self-report questionnaires. Short descriptions of the questionnaires are provided, as they are described in more detail elsewhere (Geelen et al., 2016).

\subsubsection{Patient characteristics}

The following factors were assessed; age (years), gender (male/female) and having insulin treatment for DM II (yes/no). 


\subsubsection{Pain}

Duration of complaints of neuropathic pain was assessed (months). In addition, current pain intensity was measured using a Visual Analogue Scale (VAS), ranging from $0-10$.

\subsubsection{Disability}

Disability was measured using the pain disability index (PDI). This 7-item questionnaire investigates the magnitude of the self-reported disability in different domains such as work, leisure time, activities of daily living (ADL) and sports. PDI has shown to be reliable (internal consistency, Cronbach's $\alpha=0.86$ ) and correlates significantly with objective indices of disability such as time spent in bed, psychosomatic symptoms, stopping activities because of pain, work status, pain duration, usual pain intensity, quality of life and education ( $r=0.74)$ (Tait et al., 1990).

\subsubsection{Quality of life}

Quality of life was measured using the Norfolk Quality of Life Questionnaire, Diabetic Neuropathy Version, QOL-DN (Vinik et al., 2005), a self-administered questionnaire designed to capture and quantify the perceived impact of diabetic neuropathy on the quality of life, as well as physical and psychosocial functioning. Internal consistency of the various domains using Cronbach's $\alpha$ showed to be 0.6-0.8 (Vinik et al., 2005).

\subsubsection{Specific fears were measured using the following questionnaires:}

2.2.5.1 Fear of hypoglycaemia. Fear for hypoglycaemia was measured using the Dutch version of the Hypoglycaemia Fear Survey (HFS). For the purpose of this study, only the 13-item 'worry scale' was used. The internal consistency of this questionnaire has shown to be high (Cronbach's $\alpha=0.92$ ) (Snoek et al., 1996). Temporal reliability (test-retest) has shown to be $r=0.74$ for the total HFS and $r=0.63$ for the 'worry scale' (Gonder-Frederick et al., 2011).

2.2.5.2 Fear of pain. The short version of the Pain Anxiety Symptom Scale (PASS-20) measures the importance of fear for pain in persistent pain behaviour (McCracken and Dhingra, 2002). The PASS-20 has shown strong internal consistency; Cronbach's $\alpha$ for avoidance behaviour $=0.75$, for fear $=0.82$, for somatic fear $=0.81$ and for cognitive fear $=0.86$, and total Cronbach's $\alpha$ of 0.91
(McCracken and Dhingra, 2002). Test-retest reliability has shown to be good ( $r=0.86$ ) (Kisacik et al., 2015).

2.2.5.3 Kinesiophobia. Kinesiophobia was measured using the Dutch version of the 17-item Tampa Scale of Kinesiophobia (TSK). Test-retest reliability has shown to range from $r=0.64-0.80$ (SwinkelsMeewisse et al., 2003). The internal consistency of the TSK has shown to be good (Cronbach's $\alpha=0.81$; Roelofs et al., 2004).

2.2.5.4 Fear of fatigue. Fear of fatigue was measured using the Short Tampa scale for Fear of Fatigue (TSF). Internal consistency of the TSF has shown to be sufficient (Cronbach's $\alpha=0.80$; Nijs et al., 2012) and test-retest reliability has shown to be good (ICC $=0.83$; Nijs and Thielemans, 2008).

2.2.5.5 Fear of falling. Fear of falling was measured by the 'Falls Efficacy Scale-International' (FES-I), which measures confidence in performing activities without falling in daily living (e.g. cleaning the house). The internal consistency of the FES-I has shown to be high (Cronbach's $\alpha$ 0.96) and the test-retest reliability has shown to be high $($ ICC $=0.82-0.93$; Kempen et al., 2007; Bula et al., 2008).

2.2.5.6 Fear of negative evaluation. Fear for negative evaluation is measured by the 'Brief Fear of Negative Evaluation Scale' (BFNE, short form; Carleton et al., 2011). Fear of negative evaluation is defined as fear of negative evaluation as apprehension about others' evaluations, distress over their negative evaluations, avoidance of evaluative situations and the expectation that others will evaluate oneself negatively (Carleton et al., 2006). Internal consistency of the BFNE has shown to be excellent (Cronbach's $\alpha=0.96$; Carleton et al., 2011). The scale obtained excellent inter-item reliability $(\alpha=0.97)$ and 2 -week test-retest reliability $(r=0$ .94; Collins et al., 2005).

\subsection{Statistical analysis}

Data were analysed using Statistical Package for Social Sciences for Windows, version 22.0. IBM SPSS Statistics for Windows, Version 22.0. Armonk, NY: IBM Corp. The study questionnaires HFS, PASS-20, TSK, FES-I, TSF and BFNE were scored according to the standard scoring guidelines. Descriptive statistics were used to describe the study sample; means and 
standard deviations for normally distributed variables, medians and interquartile ranges for skewed variables and numbers and percentages for categorical variables, as appropriate. Comparisons between two groups were performed using the Student's $t$-test for independent samples. If there was $<25 \%$ nonresponse on a variable, mean imputation was performed to account for missing data in total scores. If there was $>25 \%$ non-response, the variable was registered as missing value. As data of the HFS, PASS, BFNE and FES-I were skewed, natural logarithmic transformation was applied prior to analyses.

To determine significantly associated variables for the linear regression model for QOL-DN and PDI, respectively, Spearman correlation analyses were performed including all confounders (age, gender, insulin treatment, pain intensity and duration of the pain) and all fears (HFS, PASS, TSK, FES-I, TSF and BFNE).

Linear regression models were used to assess which of the fears contributed significantly to QOL-DN and PDI, respectively. First, a baseline model was constructed including all confounders, fears (HFS, PASS, TSK, FES-I, TSF and BFNE) and QOL-DN or PDI, respectively. In addition, stepwise backward regression analyses were performed to construct a final model in which confounders were retained, but the fears HFS, PASS, TSK, FES-I, TSF and BFNE were systematically eliminated. A limit value for elimination in the backward regression analyses was set at $p<0.05$. In this final model, only statistically significant variables were retained. A two-sided $p$-value $<0.05$ was considered statistically significant. The maximum coefficient of determination $\left(R^{2}\right)$ was taken into account for each analysis. All the variable inflation factors (VIF) were checked and had to be $<3$.

\section{Results}

\subsection{Patients}

A total of 2142 patients were invited, of which 388 responded and 237 expressed their willingness to participate. Of the 151 patients who resigned, 94 patients/caregivers provided a reason for not participating [no neuropathic pain $(n=54)$, type I DM $(n=23)$, death $(n=9)$, personal circumstances $(n=4)$, moved to a different address $(n=2)$, phantom limb pain $(n=1)$, or no DM $(n=1)]$. Of the 237 patients who received a questionnaire, 183 actually completed and returned the questionnaire, and of these 154 patients met the inclusion/exclusion criteria and were eligible to this study (see Fig. 1).

\subsection{Baseline characteristics}

Baseline characteristics and descriptive statistics of fear-related outcomes are shown in Table 1. There were no differences between men and women regarding the baseline characteristics, pain-related and fear-related outcomes $(p>0.05$ for all variables, data not shown).

\subsection{Correlations and linear backward regression models}

Mean imputation was performed for the following variables: QOL-DN $(n=29)$, PDI $(n=12)$, HFS $(n=14)$, PASS $(n=13), \quad$ TSK $\quad(n=3), \quad$ FES-I $(n=12), \operatorname{TSF}(n=2)$ and BFNE $(n=2)$.

Spearman correlations were calculated to construct a correlation matrix for all variables and QoL (Table 2) and disability (Table 3 ). The results show that each of the fears (fear of hypoglycaemia (HFS), fear of pain (PASS), kinesiophobia (TSK), fear of negative evaluation (BFNE), fear of falling (FES-I) and fear of fatigue (TSF)) significantly correlated with QOL-DN $(p<0.001$ for all variables, Table 2$)$ and PDI $(p<0.001$ for all variables, Table 3$)$.

Linear regression analyses including all confounders and fears, were performed to assess the association of the fears with QoL and disability, respectively. Duration of complaints, pain intensity and fear of falling were significantly associated with QoL $(\beta=0.131, p=0.042 ; \beta=0.239, p<0.001$ and $\beta=0.348, \quad p<0.001$ resp.). The final model explained $60.3 \%$ of the total variance (adjusted $\left.R^{2}=0.603\right)$. The full model is shown in Table 4. As mentioned before, mean imputation was performed in 29 cases of QOL-DN. An additional analysis excluding these 29 subjects showed similar results as compared to the analysis including the imputed data; duration of complaints, pain intensity and fear of falling were all significantly associated with QoL $(\beta=0.121, \quad p=0.043 ; \quad \beta=0.252, \quad p<0.001 ; \quad \beta=$ $0.363, p<0.001$ resp.). In addition to this, the fear of hypoglycaemia showed a statistically significant contribution to the association of fears with QoL ( $\beta=0.172, p=0.027)$ and the final model explained $59.2 \%$ of the total variance (adjusted $R^{2}=0.592$ ).

Male gender, pain intensity and fear of falling were significantly associated with disability $(\beta=-0.122, \quad p=0.048 ; \quad \beta=0.250, \quad p<0.01$ and $\beta=0.443, \quad p<0.001$ resp.). The final model explained $52.6 \%$ of the total variance (adjusted $\left.R^{2}=0.526\right)$. The full model is shown in Table 5 .

Finally, stepwise backward regression analyses were performed. The final model for QoL and 


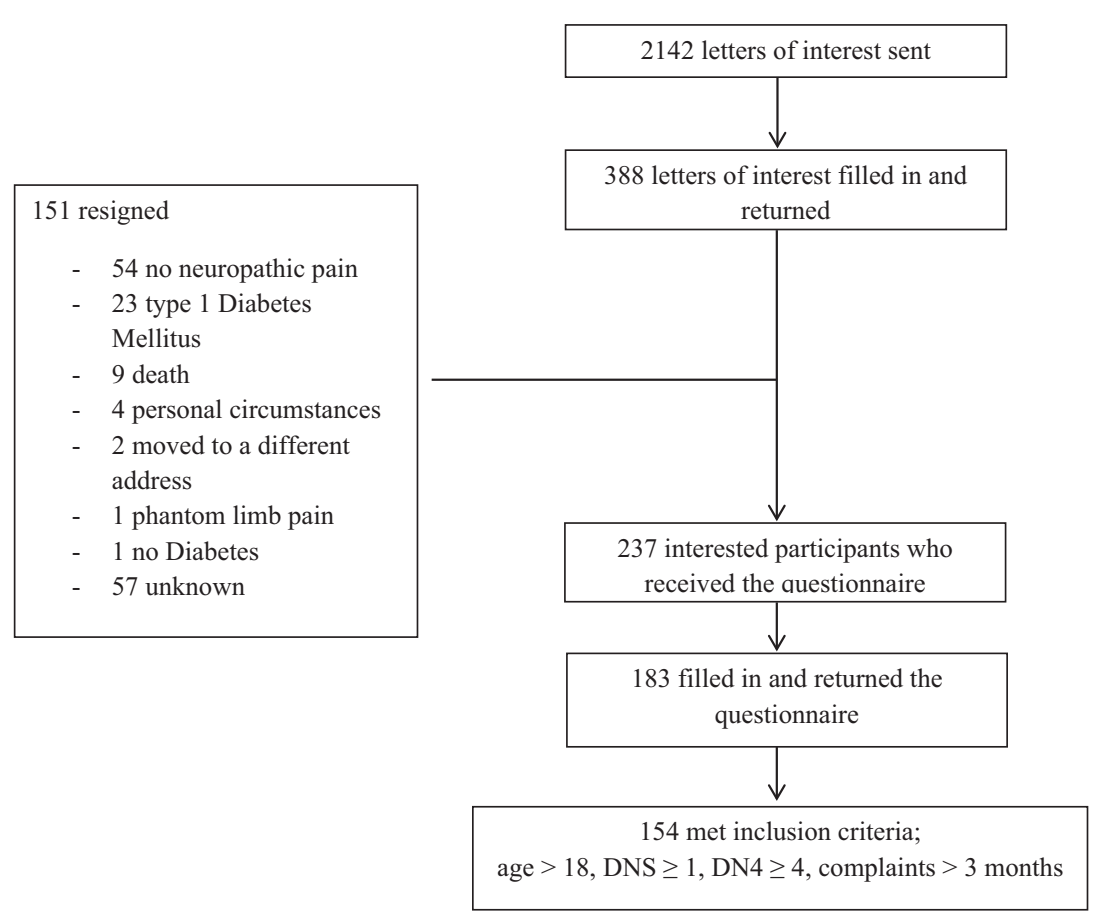

Figure 1 Flowchart of inclusion procedure.

Table 1 Baseline characteristics.

\begin{tabular}{llll}
\hline & & $N$ \\
\hline Demographic & Age & 154 & $65.7 \pm 6.6$ \\
variables & Gender (Male/Female) & 154 & $96(62 \%) / 58(38 \%)$ \\
& Insulin treatment & 154 & $100(65 \%)$ \\
Pain-related & Duration of & 144 & $72.3 \pm 57.6$ \\
measures & complaints & & \\
& Pain intensity & 153 & $4.8 \pm 2.0$ \\
Consequences & QOL-DN & 131 & $52.6 \pm 26.1$ \\
in daily life & PDI & 150 & $32.4 \pm 17.0$ \\
Fears & HFS & 151 & $13.5(3.5-23.0)$ \\
& PASS-20 & 152 & $25.0(10.7-39.3)$ \\
& TSK & 149 & $38.1 \pm 8.0$ \\
& FES-I & 150 & $27.0(20.5-33.5)$ \\
& TSF & 153 & $16.3 \pm 5.5$ \\
& BFNE & 153 & $11.0(6.1-10.9)$ \\
\hline
\end{tabular}

Data are presented as $n(\%)$, mean \pm SD or median (interquartile range), as appropriate. Age (years); Duration of complaints (months); pain intensity (VAS 0-10). QOL-DN, Norfolk Quality of Life Questionnaire; PDI, Pain Disability Index; HFS, Hypoglycaemia Fear Survey; PASS-20, Pain Anxiety Symptom Scale; TSK, Tampa Scale of Kinesiophobia; FES-I, Falls Efficacy Scale - International; TSF, Tampa Scale of Fatigue; BFNE, Brief Fear of Negative Evaluation Scale.

confounders (age, gender, insulin treatment, duration of complaints and pain intensity), showed that fear of fatigue, fear of hypoglycaemia and fear of falling were retained as statistically significant contributing factors $(\beta=0.134, p=0.045 ; \beta=0.216$, $p=0.003$ and $\beta=0.385, p<0.001$ resp., data not shown). Also pain intensity showed to have a statistically significant contribution to the model of QOLDN $(\beta=0.253, \quad p<0.001)$. The final model explained $60.2 \%$ of the total variance (adjusted $R^{2}=0.602$, data not shown). The final model of the stepwise backward regression analysis for disability and confounders, showed that only fear of falling was retained in the model $(\beta=0.540, p<0.001)$. In this model, pain intensity and gender also showed a statistically significant contribution to the model $(\beta=0.283, p<0.001 ; \beta=-0.135, p=0.025)$. The final model explained $52.3 \%$ of the total variance (adjusted $R^{2}=0.523$, data not shown). In both models, age, insulin treatment and duration of complaints showed no statistically significant contribution.

In all models, VIFs were checked and were all $<3$.

\section{Discussion and conclusions}

This study illustrates that patients with PDN seem to suffer from various fears, such as fear of hypoglycaemia, kinesiophobia, fear of pain, fear of negative evaluation, fear of falling and fear of fatigue, and that some of these fears are associated with less QoL and increased disability in patients with PDN. Univariate analyses showed that all these fears were significantly and negatively associated with QoL and 
Table 2 Correlation Matrix QOL-DN.

\begin{tabular}{|c|c|c|c|c|c|c|c|c|c|c|c|c|}
\hline & QOL-DN & Age & Gender & Insulin & Duration & $\begin{array}{l}\text { Pain } \\
\text { intensity }\end{array}$ & TSK & TSF & HFS & PASS-20 & FES-I & BFNE \\
\hline QOL-DN & 1.000 & -0.037 & 0.042 & 0.165 & $0.375^{\star \star}$ & $0.491 * \star$ & $0.523^{\star \star}$ & $0.388^{* *}$ & $0.582^{\star \star}$ & $0.711^{\star *}$ & $0.707^{* *}$ & $0.458^{\star *}$ \\
\hline Age & & 1.000 & -0.031 & -0.005 & 0.000 & -0.009 & 0.014 & $0.178^{*}$ & -0.149 & -0.012 & 0.018 & -0.136 \\
\hline Gender & & & 1.000 & 0.028 & 0.048 & 0.083 & -0.060 & -0.167 & 0.067 & 0.025 & 0.048 & $0.208^{*}$ \\
\hline $\begin{array}{l}\text { Insulin } \\
\text { treatment }\end{array}$ & & & & 1.000 & 0.116 & 0.068 & 0.119 & $0.188^{*}$ & 0.170 & 0.110 & $0.184^{\star}$ & 0.045 \\
\hline $\begin{array}{l}\text { Duration of } \\
\text { symptoms }\end{array}$ & & & & & 1.000 & $0.226^{*}$ & $0.197 *$ & 0.074 & $0.209 *$ & $0.241^{* *}$ & $0.322^{\star \star}$ & 0.032 \\
\hline Pain intensity & & & & & & 1.000 & $0.325^{\star \star}$ & 0.149 & $0.315^{\star \star}$ & $0.441^{* *}$ & $0.395^{\star \star}$ & $0.223^{*}$ \\
\hline TSK & & & & & & & 1.000 & $0.665^{\star \star}$ & $0.480^{\star \star}$ & $0.583^{* *}$ & $0.535^{\star \star}$ & $0.395^{\star \star}$ \\
\hline TSF & & & & & & & & 1.000 & $0.313^{\star \star}$ & $0.437 * \star$ & $0.366^{\star \star}$ & $0.257^{\star \star *}$ \\
\hline HFS & & & & & & & & & 1.000 & $0.639 * *$ & $0.542^{\star \star}$ & $0.574^{\star *}$ \\
\hline PASS & & & & & & & & & & 1.000 & $0.703^{\star *}$ & $0.563^{\star *}$ \\
\hline FES-I & & & & & & & & & & & 1.000 & $0.467^{\star *}$ \\
\hline BFNE & & & & & & & & & & & & 1.000 \\
\hline
\end{tabular}

QOL-DN, Norfolk Quality of Life Questionnaire; TSK, Tampa Scale of Kinesiophobia; TSF, Tampa Scale of Fatigue; HFS, Hypoglycaemia Fear Survey; PASS-20, Pain Anxiety Symptom Scale; FES-I, Falls Efficacy Scale - International; BFNE, Brief Fear of Negative Evaluation Scale.

Correlations are presented as $R$-values.

${ }^{* *}$ Correlation is significant at the 0.01 level (2-tailed).

${ }^{*}$ Correlation is significant at the 0.05 level (2-tailed).

Table 3 Correlation matrix PDI.

\begin{tabular}{|c|c|c|c|c|c|c|c|c|c|c|c|c|}
\hline & PDI & Age & Gender & Insulin & Duration & $\begin{array}{l}\text { Pain } \\
\text { intensity }\end{array}$ & TSK & TSF & HFS & PASS-20 & FES-I & BFNE \\
\hline PDI & 1.000 & 0.025 & -0.081 & 0.136 & $0.292^{\star \star}$ & $0.495^{\star \star}$ & $0.484^{\star *}$ & $0.408^{\star *}$ & $0.409^{\star *}$ & $0.610^{\star *}$ & $0.659 * *$ & $0.281^{\star *}$ \\
\hline Age & & 1.000 & 0.018 & 0.051 & -0.015 & 0.008 & 0.025 & 0.136 & -0.099 & 0.003 & 0.024 & -0.166 \\
\hline Gender & & & 1.000 & 0.053 & 0.020 & 0.035 & -0.049 & -0.126 & 0.073 & 0.004 & 0.070 & $0.177^{\star}$ \\
\hline $\begin{array}{l}\text { Insulin } \\
\text { treatment }\end{array}$ & & & & 1.000 & 0.079 & 0.049 & 0.103 & 0.124 & $0.195^{\star}$ & 0.095 & 0.136 & 0.021 \\
\hline $\begin{array}{l}\text { Duration of } \\
\text { symptoms }\end{array}$ & & & & & 1.000 & $0.257 * \star$ & $0.198^{\star}$ & 0.059 & $0.210^{*}$ & 0.231 ** & $0.277^{\star *}$ & -0.007 \\
\hline Pain intensity & & & & & & 1.000 & $0.326^{* *}$ & 0.160 & $0.277^{\star \star}$ & $0.444^{* *}$ & $0.404^{\star \star}$ & 0.154 \\
\hline TSK & & & & & & & 1.000 & $0.655^{\star \star}$ & 0.491 ** & $0.603 * *$ & $0.534 \star \star$ & $0.379 * \star$ \\
\hline TSF & & & & & & & & 1.000 & $0.320 * *$ & $0.464^{\star \star}$ & $0.415^{\star \star}$ & $0.261 * \star$ \\
\hline HFS & & & & & & & & & 1.000 & $0.642^{\star *}$ & $0.497^{\star *}$ & $0.547^{\star \star *}$ \\
\hline PASS & & & & & & & & & & 1.000 & $0.715^{\star \star}$ & $0.544^{\star \star}$ \\
\hline FES-I & & & & & & & & & & & 1.000 & $0.433^{* *}$ \\
\hline BFNE & & & & & & & & & & & & 1.000 \\
\hline
\end{tabular}

PDI, Pain Disability Index; TSK, Tampa Scale of Kinesiophobia; TSF, Tampa Scale of Fatigue; HFS, Hypoglycaemia Fear Survey; PASS-20, Pain Anxiety Symptom Scale; FES-I, Falls Efficacy Scale - International; BFNE, Brief Fear of Negative Evaluation Scale.

Correlations are presented as $R$-values.

${ }^{* *}$ Correlation is significant at the 0.01 level (2-tailed).

${ }^{*}$ Correlation is significant at the 0.05 level (2-tailed).

were positively associated with disability. More specifically, multivariate analyses showed that fear of falling, duration of complaints and pain intensity were the most important factors being negatively associated with QoL, while fear of falling, male gender and pain intensity were significantly associated with disability in patients with PDN. This study highlights the great burden of PDN in daily life, as reflected by the scores of disability and QoL (Soer et al., 2013). Our findings could be relevant for clinical practice as it may provide a basis for a theoretical framework on the psychosocial consequences of PDN. This framework enables us to design a treatment strategy that could directly target these fears (e.g. behavioural interventions according to the principles of exposure in vivo (den Hollander et al., 2016), and by doing so, could improve physical and psychosocial well-being in these patients. 
Table 4 Linear regression analyses of fears and QoL $(n=122)$.

\begin{tabular}{lcll}
\hline & Standardized beta & $p$-Value & $R^{2}$ \\
\hline Age & -0.045 & 0.467 & 0.603 \\
Gender & -0.011 & 0.857 & \\
Insulin Treatment & 0.014 & 0.817 & \\
Duration of complaints & 0.131 & $0.042^{*}$ & \\
Pain Intensity & 0.239 & $0.000^{*}$ & \\
TSK & -0.036 & 0.705 & \\
TSF & 0.130 & 0.137 & \\
HFS & 0.152 & 0.062 & \\
PASS & 0.078 & 0.397 & \\
FES-I & 0.348 & $0.000 *$ & \\
BFNE & 0.101 & 0.175 & \\
\hline
\end{tabular}

Determinants of QOL, as measured with QOL-DN; Norfolk Quality of Life Questionnaire, Diabetic Neuropathy Version. Age (years); Gender $(0=$ male, $1=$ female $) ;$ Insulin treatment $(0=$ no, $1=$ yes $)$; Duration of complaints (months), Pain Intensity (VAS 0-10); TSK, Tampa Scale of Kinesiophobia; TSF, Tampa Scale for Fatigue, HFS, Hypoglycaemia Symptom Scale; PASS, Pain Anxiety Symptom Scale; FES-I, Falls Efficacy Scale - International; BFNE, Brief Fear of Negative Evaluation Scale.

${ }^{*} p<0.05$.

Table 5 Linear regression analyses of fears and disability $(n=136)$.

\begin{tabular}{lcll}
\hline & Standardized beta & $p$-value & $R^{2}$ \\
\hline Age & 0.001 & 0.993 & 0.526 \\
Gender & -0.122 & $0.048^{*}$ & \\
Insulin treatment & 0.044 & 0.481 & \\
Duration of complaints & 0.055 & 0.395 & \\
Pain intensity & 0.250 & $0.000^{*}$ & \\
TSK & 0.032 & 0.743 & \\
TSF & 0.084 & 0.334 & \\
HFS & 0.029 & 0.738 & \\
PASS & 0.078 & 0.426 & \\
FES-I & 0.443 & $0.000 *$ & 0.938 \\
BFNE & 0.006 & &
\end{tabular}

Determinants of Disability as measured with PDI; Pain Disability Index. Age (years); Gender $(0=$ male, $1=$ female); Insulin treatment $(0=$ no, 1 = yes); Duration of complaints (months), Pain Intensity (VAS 0-10); TSK, Tampa Scale of Kinesiophobia; TSF, Tampa Scale for Fatigue; HFS, Hypoglycaemia Symptom Scale; PASS, Pain Anxiety Symptom Scale; FES-I, Falls Efficacy Scale - International; BFNE, Brief Fear of Negative Evaluation Scale.

$*_{p}<0.05$.

Chronic pain is a subjective experience that is known to affect cognitive and emotional dimensions (Crombez et al., 2012). Neuropathic pain has shown to be particularly distressing, as it is associated with a high degree of suffering and does not generally decline over time (Gore et al., 2005). Unfortunately, there is no cure for diabetic neuropathy. Treatment approaches include decelerating the progressive loss of nerve function through maintenance of glycaemic control and pain management (Javed et al., 2015). Pain medication such as anti-depressants, anti-epileptics and opioids are recommended. However, treatment effects are not always sufficient and side effects occur frequently (Finnerup et al., 2015).

In the biopsychosocial perspective, chronic pain is influenced by biological, psychological and social factors, resulting in individual differences in motoric, cognitive and psycho-physiological responses (Vlaeyen et al., 2002). Fears play an important role in the interpretation and experience of chronic pain, as is illustrated by the fear-avoidance model (Vlaeyen et al., 2002). This model proposes a theoretical framework that addresses the way a patient interprets its pain. In general, if pain is interpreted as non-threatening, patients are likely to stay engaged in daily activities. If, however, patients misinterpret pain as being threatening, a vicious cycle of catastrophic thinking may be initiated leading to excessive fear of pain/injury, resulting in avoidance of physical activities, disuse, depression and disability (Crombez et al., 2012). Studies have shown that specific fears such as 'fear of movement' or 'fear of (re)injury' can have a disabling effects in patients with chronic musculoskeletal pain (Vlaeyen et al., 2002) and fear has proven to be a strong predictor for disability and depression on the long run (Leeuw et al., 2007). To the best of our knowledge, this is the first study that makes an attempt to specify fears in patients with PDN.

In our study, PDN was associated with a lower QoL (Geelen et al., 2017) and disability (Abbott et al., 2011). This sample of Dutch patients with PDN reported a mean QoL score comparable to other studies in patients with PDN (Currie et al., 2007). The mean score of disability was comparable to scores of patients with other pain syndromes (Köke et al., 2016). Greater pain levels in PDN have shown to correspond with higher symptom levels of anxiety and depression, more sleep problems and problems related to physical and mental functioning (Benbow et al., 1998; Galer et al., 2000). Furthermore, pain intensity was significantly associated with diminished QoL and disability.

Diabetic neuropathy can lead to sensory and motor deficits, altered gait stability and balance impairments (Allet et al., 2008), potentially resulting in an increased risk of falling (Lalli et al., 2013). In our study, fear of falling showed to be an important predictor for both disability and QoL as this fear was highly associated with both outcomes in the multivariate analyses. Fear of falling can reduce QoL by causing distress, activity restriction and social 
isolation (Kempen et al., 2008). Previous research has found a graded relationship between diabetes status and the risk of falling, in which a threefold increased risk of recurrent falls was reported in persons with diabetes compared to persons without diabetes (Volpato et al., 2005). That study concluded that lower extremity pain, amongst which PDN, is one of the major risk factors for falls, together with insulin therapy and high body mass index. Paradoxically, the fear of falling itself has shown to be a risk factor for falls and injury, and can lead to avoidance behaviour, activity restriction and subsequent deconditioning (Bruce et al., 2015). Despite the fact that fear of falling appears to be an adequate protection mechanism in patients with PDN, it also seems to amplify the risk of falling as it may lead to dysfunctional gait adjustments. The current results suggest that it is very important for clinicians to address falling and the fear of falling when treating patients with PDN. Fear of falling is a fear that could be treated with a behavioural intervention such as exposure in vivo (Wetherell et al., 2016; ScheffersBarnhoorn et al., 2017). In this treatment, the patient will be exposed repeatedly to a situation in which the fear usually occurs. Absence of aversive consequences will lead to extinction of the specific fear (de Jong et al., 2005a).

Maintenance of tight glycaemic control is of great importance in the management of DM and the prevention of long-term comorbidities associated with DM (Maser et al., 1989). However, tight glycaemic control may also increase the number of hypoglycaemic episodes. In clinical practice, treating fear of hypoglycaemia seems to be challenging as studies have shown that experiencing even a single hypoglycaemia symptom has a significant impact on patients' immediate health status with longer term consequences (e.g. fear of future hypoglycaemia and self-directed behavioural changes to manage hypoglycaemia symptoms) (Williams et al., 2012). As a result, diabetic patients may tend to maintain their blood glucose levels within a 'safety margin' which is often higher than recommended, hereby maintaining hyperglycaemia (Sakane et al., 2015). To reduce the risk of having an episode of hypoglycaemia during exercise, a patient may also avoid physical activity. Therefore, being afraid of a hypoglycaemic episode can lead to behavioural changes in the management of diabetes and metabolic control, potentially resulting in the aggravation of diabetes-related complications such as neuropathy, nephropathy and retinopathy (Maser et al., 1989). It seems to be of great importance to acknowledge and treat fear of hypoglycaemia in patients with $\mathrm{PDN}$, to increase physical activity, QoL and reduce diabetes-related complications in the future. In this study, fear of hypoglycaemia was associated with diminished QoL (Williams et al., 2012) in the stepwise backward regression model and the dataset without the imputed data.

In patients with diabetes, fatigue is reported twice as often as compared to patients without diabetes (Weijman et al., 2003). Fatigue in diabetes is related to poor self-reported health and self-management of diabetes (Fritschi et al., 2012). Fear of fatigue showed to be significantly associated with QoL in the in the stepwise backward regression model. Fear of pain, kinesophobia and fear of negative evaluation were all independently associated with QoL and disability, but were not retained in the multivariate analyses.

Age and insulin treatment showed no significant contribution in the associations of fears with QoL or disability. This is in contrast to our previous study in the same sample of patients with PDN, in which we found an association of insulin treatment with pain catastrophizing, QoL and disability, respectively (Geelen et al., 2017). In the latter study, we explained this association by the fact that insulin treatment, being a burdensome method of administration, can be considered as a parameter for severity of DM II. On the basis of these results, we expected that insulin treatment would also be associated with diabetes and/or pain-related fears. However, this study suggests that fears do not play a role in this mechanism.

This study has several limitations. First, diabetesrelated information is based on self-report as subjects were derived from an already existing database containing patients with DM. To improve accuracy, we have used multiple items (DNS $>1$ and DN4 $\geq 4$ ) to diagnose PDN. Unfortunately, there was no information available on diabetes-related complications such as retinopathy or nephropathy. In future studies, it would be recommended to diagnose PDN based on a clinical history and physical examination. Furthermore, mean imputation was performed on several cases of the variable QOL-DN. Additional analysis excluding the imputed data showed that our results were robust for the fear of falling. The fact that fear of fatigue and fear of hypoglycaemia also contributed to the association of QoL with fears in the sample without imputed data, should be further researched in a new sample. Finally, this study has a cross-sectional design in which the dependent and independent variables are simultaneously assessed. For this 
reason, conclusions on a causal relationship or a chronological order have to be interpreted with caution.

In conclusion, this study shows that patients with PDN may suffer from different fears that seem to be associated with a significant psychosocial burden. Especially the fear of falling has shown to be an important potential determinant for QoL and/or disability in this study. Despite the limitations of this study, our findings could be relevant to clinical practice as the fear of falling is a fear that can be targeted with treatment, e.g. with behavioural interventions according to the principles of exposure in vivo (de Jong et al., 2005b; den Hollander et al., 2010, 2016).

\section{Author contributions}

All authors listed concur with the submitted version of the manuscript and with the listing of the authors. Authorship credit is based on important contributions in one or more of the following areas: conception and design, collection, analysis and interpretation of data, drafting of the manuscript or making intellectual contributions to its content. None of the authors have any financial or other relationship that might lead to a conflict of interest. This manuscript is not simultaneously being submitted elsewhere.

C.G., first author, responsible for the integrity of the work as a whole, from inception to published article and contributed to the conception and design, collection, analysis and interpretation of data, drafting of the manuscript and making intellectual contributions to its content.

R.S. contributed to the conception and design, analysis and interpretation of data, drafting of the manuscript or making intellectual contributions to its content.

S.S. involved in the interpretation of data and drafting of the manuscript.

J.B. was responsible for the conception and design, collection of data and making intellectual contributions to its content.

M.G. performed the conception and design, analysis and interpretation of data and making intellectual contributions to its content.

J.V. played a role in the conception and design, analysis and interpretation of data, drafting of the manuscript and making intellectual contributions to its content.

\section{References}

Abbott, C.A., Malik, R.A., van Ross, E.R., Kulkarni, J., Boulton, A.J. (2011). Prevalence and characteristics of painful diabetic neuropathy in a large community-based diabetic population in the U.K. Diabetes Care 34, 2220-2224.

Allet, L., Armand, S., Golay, A., Monnin, D., De Bie, R., De Bruin, E. (2008). Gait characteristics of diabetic patients: A systematic review. Diabetes Metab Res Rev 24, 173-191.
Benbow, S.J., Wallymahmed, M.E., Macfarlane, I.A. (1998). Diabetic peripheral neuropathy and quality of life. QJM 91, 733-737.

Boulton, A.J., Malik, R.A., Arezzo, J.C., Sosenko, J.M. (2004). Diabetic somatic neuropathies. Diabetes Care 27, 1458-1486.

Bruce, D., Hunter, M., Peters, K., Davis, T., Davis, W. (2015). Fear of falling is common in patients with type 2 diabetes and is associated with increased risk of falls. Age Ageing 44, 687-690.

Bula, C.J., Martin, E., Rochat, S., Piot-Ziegler, C. (2008). Validation of an adapted falls efficacy scale in older rehabilitation patients. Arch Phys Med Rehabil 89, 291-296.

Carleton, R.N., McCreary, D.R., Norton, P.J., Asmundson, G.J.G. (2006). Brief fear of negative evaluation scale-revised. Depress Anxiety 23, 297-303.

Carleton, R.N., Collimore, K.C., McCabe, R.E., Antony, M.M. (2011). Addressing revisions to the Brief Fear of Negative Evaluation scale: Measuring fear of negative evaluation across anxiety and mood disorders. J Anxiety Disord 25, 822-828.

Collins, K.A., Westra, H.A., Dozois, D.J., Stewart, S.H. (2005). The validity of the brief version of the Fear of Negative Evaluation Scale. J Anxiety Disord 19, 345-359.

Collins, M.M., Corcoran, P., Perry, I.J. (2009). Anxiety and depression symptoms in patients with diabetes. Diabet Med 26, 153-161.

Crombez, G., Eccleston, C., Van Damme, S., Vlaeyen, J., Karoly, P. (2012). Fear-avoidance model of chronic pain: The next generation. Clin J Pain 28, 475-483.

Currie, C., Poole, C., Woehl, A., Morgan, C.L., Cawley, S. et al. (2007). The financial costs of healthcare treatment for people with Type 1 or Type 2 diabetes in the UK with particular reference to differing severity of peripheral neuropathy. Diabet Med 24, 187-194.

Daousi, C., MacFarlane, I.A., Woodward, A., Nurmikko, T.J., Bundred, P.E., Benbow, S.J. (2004). Chronic painful peripheral neuropathy in an urban community: A controlled comparison of people with and without diabetes. Diabet Med 21, 976-982.

Davies, M., Brophy, S., Williams, R., Taylor, A. (2006). The prevalence, severity, and impact of painful diabetic peripheral neuropathy in type 2 diabetes. Diabetes Care 29, 1518-1522.

Finnerup, N.B., Attal, N., Haroutounian, S., McNicol, E., Baron, R. et al. (2015). Pharmacotherapy for neuropathic pain in adults: A systematic review and meta-analysis. Lancet Neurol 14, 162-173.

Fritschi, C., Quinn, L., Hacker, E., Penckofer, S.M., Wang, E., Foreman, M., Ferrans, C.E. (2012). Fatigue in women with type 2 diabetes. Diabetes Educ 38, 662-672.

Galer, B.S., Gianas, A., Jensen, M.P. (2000). Painful diabetic polyneuropathy: Epidemiology, pain description, and quality of life. Diabetes Res Clin Pract 47, 123-128.

Geelen, C.C., Brouwer, B.A., Hoeijmakers, J.G., Faber, C.G., Merkies, I.S., Verbunt, J.A. (2016). Painful diabetic neuropathy anxiety rasch-transformed questionnaire (PART-Q30). J Peripher Nerv Syst 21, 96-104.

Geelen, C.C., Kindermans, H.P., van den Bergh, J.P., Verbunt, J.A. (2017). Perceived physical activity decline as a mediator in the relationship between pain catastrophizing, disability, and quality of life in patients with painful diabetic neuropathy. Pain Pract 17, $320-328$.

Gonder-Frederick, L.A., Schmidt, K.M., Vajda, K.A., Greear, M.L., Singh, H., Shepard, J.A., Cox, D.J. (2011). Psychometric properties of the hypoglycemia fear survey-ii for adults with type 1 diabetes. Diabetes Care 34, 801-806.

Gore, M., Brandenburg, N.A., Dukes, E., Hoffman, D.L., Tai, K.S., Stacey, B. (2005). Pain severity in diabetic peripheral neuropathy is associated with patient functioning, symptom levels of anxiety and depression, and sleep. J Pain Symptom Manage 30, 374-385.

den Hollander, M., de Jong, J.R., Volders, S., Goossens, M.E., Smeets, R.J., Vlaeyen, J.W. (2010). Fear reduction in patients with chronic pain: A learning theory perspective. Expert Rev Neurother 10, 17331745.

den Hollander, M., Goossens, M., de Jong, J., Ruijgrok, J., Oosterhof, J. et al. (2016). Expose or protect? A randomized controlled trial of exposure in vivo vs pain-contingent treatment as usual in patients with complex regional pain syndrome type 1. Pain 157, 2318-2319. 
Javed, S., Alam, U., Malik, R.A. (2015). Burning through the pain: Treatments for diabetic neuropathy. Diabetes Obes Metab 17, 11151125 .

de Jong, J.R., Vlaeyen, J.W., Onghena, P., Cuypers, C., den Hollander, M., Ruijgrok, J. (2005a). Reduction of pain-related fear in complex regional pain syndrome type I: The application of graded exposure in vivo. Pain 116, 264-275.

de Jong, J.R., Vlaeyen, J.W., Onghena, P., Goossens, M.E., Geilen, M., Mulder, H. (2005b). Fear of movement/(re)injury in chronic low back pain: Education or exposure in vivo as mediator to fear reduction? Clin J Pain 21, 9-17; discussion 69-72.

Kanera, I.M., Ruijgrok, J.M., Goossens, M.E.J.B., deJong, J.R., Verbunt, J.A., Geerts, M., Kindermans, H.P.J. (Submitted). A qualitative investigation into living with diabetic peripheral neuropathic pain: patient's experiences, beliefs, and fears.

Kempen, G.I., Zijlstra, G.A., van Haastregt, J.C. (2007). [The assessment of fear of falling with the Falls Efficacy Scale-International (FES-I). Development and psychometric properties in Dutch elderly]. Tijdschr Gerontol Geriatr 38, 204-212.

Kempen, G.I.J.M., Yardley, L., Van Haastregt, J.C.M., Zijlstra, G.A.R., Beyer, N., Hauer, K., Todd, C. (2008). The Short FES-I: A shortened version of the falls efficacy scale-international to assess fear of falling. Age Ageing 37, 45-50.

Kisacik, P., Devesan, G., Arin, G., Unal, E. (2015). AB1240-HPR Turkish Version of the short version of the pain anxiety symptom scale (PASS-20) and its test-retest reliability and validity: Preliminary report. Ann Rheum Dis 74, 1349

Köke, A., Smeets, R., Schreurs, K., van Baalen, B., de Haan, P. et al. (2016). Dutch Dataset Pain Rehabilitation in daily practice. Content, patient characteristics and reference data. Eur J Pain 21, 434-444.

Lalli, P., Chan, A., Garven, A., Midha, N., Chan, C. et al. (2013). Increased gait variability in diabetes mellitus patients with neuropathic pain. J Diabetes Complications 27, 248-254.

Leeuw, M., Goossens, M.E., Linton, S.J., Crombez, G., Boersma, K., Vlaeyen, J.W. (2007). The fear-avoidance model of musculoskeletal pain: Current state of scientific evidence. J Behav Med 30, 77-94.

Maser, R.E., Steenkiste, A.R., Dorman, J.S., Nielsen, V.K., Bass, E.B. et al. (1989). Epidemiological correlates of diabetic neuropathy. Report from Pittsburgh Epidemiology of Diabetes Complications Study. Diabetes 38, 1456-1461.

McCracken, L.M., Dhingra, L. (2002). A short version of the Pain Anxiety Symptoms Scale (PASS-20): Preliminary development and validity. Pain Res Manag 7, 45-50.

Meijer, J.W., Smit, A.J., Sonderen, E.V., Groothoff, J.W., Eisma, W.H., Links, T.P. (2002). Symptom scoring systems to diagnose distal polyneuropathy in diabetes: The Diabetic Neuropathy Symptom score. Diabet Med 19, 962-965.

Nijs, J., Thielemans, A. (2008). Kinesiophobia and symptomatology in chronic fatigue syndrome: A psychometric study of two questionnaires. Psychol Psychother 81, 273-283.

Nijs, J., Meeus, M., Heins, M., Knoop, H., Moorkens, G., Bleijenberg, G. (2012). Kinesiophobia, catastrophizing and anticipated symptoms before stair climbing in chronic fatigue syndrome: An experimental study. Disabil Rehabil 34, 1299-1305

Roelofs, J., Goubert, L., Peters, M.L., Vlaeyen, J.W., Crombez, G. (2004). The Tampa Scale for Kinesiophobia: Further examination of psychometric properties in patients with chronic low back pain and fibromyalgia. Eur J Pain 8, 495-502.

Sakane, N., Kotani, K., Tsuzaki, K., Nishi, M., Takahashi, K. et al. (2015). Fear of hypoglycemia and its determinants in insulintreated patients with type 2 diabetes mellitus. J Diabetes Investig 6, 567-570.

Scheffers-Barnhoorn, M.N., van Haastregt, J.C., Schols, J.M., Kempen, G.I., van Balen, R. et al. (2017). A multi-component cognitive behavioural intervention for the treatment of fear of falling after hip fracture (FIT-HIP): Protocol of a randomised controlled trial. BMC Geriatr 17, 71.

Snoek, F., Pouwer, F., Mollema, E., Heine, R. (1996). The Dutch fear of hypoglycemia survey. Internal consistency and validity. Gedrag Gezondh 24, 287-292.

Soer, R., Köke, A.J., Vroomen, P.C., Stegeman, P., Smeets, R.J., Coppes, M.H., Reneman, M.F. (2013). Extensive validation of the pain disability index in 3 groups of patients with musculoskeletal pain. Spine (Phila Pa 1976) 38, E562-E568.

Swinkels-Meewisse, E.J., Swinkels, R.A., Verbeek, A.L., Vlaeyen, J.W., Oostendorp, R.A. (2003). Psychometric properties of the Tampa Scale for kinesiophobia and the fear-avoidance beliefs questionnaire in acute low back pain. Man Ther 8, 29-36.

Tait, R.C., Chibnall, J.T., Krause, S. (1990). The pain disability index: Psychometric properties. Pain 40, 171-182.

Treede, R.D., Jensen, T.S., Campbell, J.N., Cruccu, G., Dostrovsky, J.O. et al. (2008). Neuropathic pain: Redefinition and a grading system for clinical and research purposes. Neurology 70, 1630-1635.

Van Damme, S., Kindermans, H. (2015). A self-regulation perspective on avoidance and persistence behavior in chronic pain: New theories, new challenges? Clin J Pain 31, 115-122.

Vinik, E.J., Hayes, R.P., Oglesby, A., Bastyr, E., Barlow, P., FordMolvik, S.L., Vinik, A.I. (2005). The development and validation of the Norfolk QOL-DN, a new measure of patients' perception of the effects of diabetes and diabetic neuropathy. Diabetes Technol Ther 7 , 497-508.

Vlaeyen, J.W., de Jong, J., Geilen, M., Heuts, P.H., van Breukelen, G. (2002). The treatment of fear of movement/(re) injury in chronic low back pain: Further evidence on the effectiveness of exposure in vivo. Clin J Pain 18, 251-261.

Volpato, S., Leveille, S.G., Blaum, C., Fried, L.P., Guralnik, J.M. (2005). Risk factors for falls in older disabled women with diabetes: The women's health and aging study. J Gerontol A Biol Sci Med Sci 60, 1539-1545.

Weijman, I., Ros, W.J.G., Rutten, G.E.H.M., Schaufeli, W.B., Schabracq, M.J., Winnubst, J.A.M. (2003). Fatigue in employees with diabetes: Its relation with work characteristics and diabetes related burden. Occup Environ Med 60, 93-98.

Wetherell, J.L., Johnson, K., Chang, D., Ward, S.R., Bower, E.S., Merz, C., Petkus, A.J. (2016). Activity, balance, learning, and exposure (ABLE): A new intervention for fear of falling. Int $J$ Geriatr Psychiatry 31, 791-798.

Williams, S.A., Shi, L., Brenneman, S.K., Johnson, J.C., Wegner, J.C., Fonseca, V. (2012). The burden of hypoglycemia on healthcare utilization, costs, and quality of life among type 2 diabetes mellitus patients. J Diabetes Complications 26, 399-406. 